\title{
Structuring evidence for invasional meltdown: broad support but with biases and gaps
}

\author{
Raul Rennó Braga (1D Lorena Gómez-Aparicio • Tina Heger • \\ Jean Ricardo Simões Vitule · Jonathan M. Jeschke
}

Received: 19 May 2017/ Accepted: 9 October 2017/Published online: 14 October 2017

(C) The Author(s) 2017. This article is an open access publication

\begin{abstract}
Negative interactions have been suggested as a major barrier for species arriving in a new habitat. More recently, positive interactions drew attention from community assembly theory and invasion science. The invasional meltdown hypothesis (IMH) introduced the idea that positive interactions among non-native species could facilitate one another's invasion, even increasing their impact upon the native community. Many studies have addressed IMH, but with contrasting results, reflecting various types of
\end{abstract}

Electronic supplementary material The online version of this article (doi:10.1007/s10530-017-1582-2) contains supplementary material, which is available to authorized users.

R. R. Braga $(\bowtie)$ · J. R. S. Vitule

Programa de Pós-Graduação em Ecologia e Conservação, Universidade Federal do Paraná, Curitiba, Brazil

e-mail: raulbraga@onda.com.br

R. R. Braga · J. R. S. Vitule

Laboratório de Ecologia e Conservação (LEC-UFPR), Depto de Engenharia Ambiental, Setor de Tecnologia, Universidade Federal do Paraná, Curitiba, Paraná, Brazil

R. R. Braga - J. M. Jeschke

Leibniz-Institute of Freshwater Ecology and Inland Fisheries (IGB), Müggelseedamm 310, 12587 Berlin, Germany

L. Gómez-Aparicio

Department of Biogeochemistry, Plant and Microbial

Ecology, Institute of Natural Resources and Agrobiology

of Seville (IRNAS), CSIC, Seville, Spain evidence on a multitude of scales. Here we use the hierarchy-of-hypotheses $(\mathrm{HoH})$ approach to differentiate key aspects of IMH, organizing and linking empirical studies to sub-hypotheses of IMH. We also assess the level of empirical support for each subhypothesis based on the evidence reported in the studies. We identified 150 studies addressing IMH. The majority of studies support IMH, but the evidence comes from studies with different aims and questions. Supporting studies at the community or ecosystem level are currently rare. Evidence is scarce for marine habitats and vertebrates. Few sub-hypotheses are questioned by more than $50 \%$ of the evaluated studies,

\footnotetext{
T. Heger

Biodiversity Research/Systematic Botany, University of

Potsdam, Maulbeerallee 1, 14469 Potsdam, Germany

T. Heger

Department of Ecology and Ecosystem Management,

Restoration Ecology, Technische Universität München

(TUM), Emil-Ramann-Str. 6, 85350 Freising, Germany

J. M. Jeschke

Department of Biology, Chemistry, Pharmacy, Institute of Biology, Freie Universität Berlin, Königin-Luise-Str. 1-3, 14195 Berlin, Germany

T. Heger · J. M. Jeschke

Berlin-Brandenburg Institute of Advanced Biodiversity

Research (BBIB), Altensteinstr. 34, 14195 Berlin,

Germany
} 
indicating that non-native species do not affect each other's survival, growth, reproduction, abundance, density or biomass in reciprocal $\mathrm{A} \leftrightarrow \mathrm{B}$ interactions. With the HoH for IMH presented here, we can monitor progress in empirical tests and evidences of IMH. For instance, more tests at the community and ecosystem level are needed, as these are necessary to address the core of this hypothesis.

Keywords Facilitation $\cdot$ Mutualism $\cdot$ Review $\cdot$ Nonindigenous $\cdot$ Exotic

\section{Introduction}

Upon arriving in a new environment, non-native species have to contend with a new set of interacting species that may constitute biotic barriers for their survival and establishment. This ecological barrier imposed on newcomers is attributed to negative interactions (e.g., direct and indirect competition, predation) with native species, but it is possible that new positive interactions (e.g., mutualism) with a native species or even with other non-natives arise that may aid in non-native species establishment, population growth and subsequent impacts (Simberloff and Von Holle 1999). Although less attention has been given to positive as compared to negative interactions (Lortie and Callaway 2009; Stachowicz 2001; Bruno et al. 2003), it is now acknowledged that positive interactions sometimes play a decisive role in shaping communities and regulating ecosystem structure and function (Halpern et al. 2007; Brooker et al. 2008; Soliveres et al. 2015).

Linking the importance of positive interactions and factors influencing non-native species success, Simberloff and Von Holle (1999) quantified how frequently positive interactions among non-native species occur compared to negative ones. Based on the widespread occurrence of positive interactions found between non-native species, Simberloff and Von Holle (1999) coined the term 'invasional meltdown' (IM) "for the process by which a group of nonindigenous species facilitate one another's invasion in various ways, increasing the likelihood of survival and/or of ecological impact, and possibly the magnitude of impact". To date, the publication of the Simberloff and Von Holle (1999) paper on the invasional meltdown hypothesis (IMH) has received 876 citations in the ISI Web of Science database (checked on 16 May 2017).

With many citations come contrasting results. An evaluation of six major hypotheses in invasion biology showed that IMH had the highest level of support (Jeschke et al. 2012). However, a recent meta-analysis on animal interactions showed that invaders most commonly reduce one another's performance rather than facilitating each other (Jackson 2015). The discrepancy between these and other studies might be due to the fact that the definition of IMH is broad, and several different aspects of the hypothesis might be tested in different ways and scales in different studies, leading authors to different conclusions. This has been pointed out as a major source of contradictory results for several hypotheses in invasion biology (Heger et al. 2013; Heger and Jeschke 2014). Words such as "various ways" which appear in the IMH definition (see the previous paragraph) are open to different interpretations. However, being broad and imprecise is a characteristic of most major hypotheses in ecology, and with few exceptions they can be tested only if further specified (Heger et al. 2013; Heger and Jeschke 2014).

Three different types of interaction scenarios involving non-native species are typically amalgamated under the umbrella of IMH. First, a non-native species facilitates any aspect of another's invasion (e.g., survival, reproduction, resource acquisition), while the latter has no detected influence on the former (+/0 interaction). Second, both species have a reciprocal effect on one another $(+/+$ interaction; as mentioned in Simberloff and Von Holle's definition). And third, more than two species interact through direct and/or indirect effects. These three interaction scenarios are typically indiscriminately cited as IM in the literature. Due to the pronounced differences between these scenarios, we argue that differentiating them is important for better understanding IM and evaluating IMH.

Studies on IMH also differ in the ecological level they consider. For example, a study might report that one non-native suppresses a native population (e.g., through predation or competition), causing local abundance of the native species to decline and consequently leading to an increase of a different non-native species' abundance through competitor release. This would constitute population-level 
evidence for IMH. Another study might report community and ecosystem alterations. For example, in the above-mentioned scenario the benefited non-native species may be a plant that alters soil properties and nutrient availability, which in turn leads to a compositional change in the community. Such evidence would address the level of communities or ecosystems instead of populations. Simberloff (2006) highlighted that most evidence available at that date was from the population level.

In order to fully understand and evaluate IMH, we need to separate these different aspects of the hypothesis (type of interaction and ecological levels) into more specific sub-hypotheses. The hierarchy-of-hypothesis $(\mathrm{HoH})$ approach (Jeschke et al. 2012; Heger et al. 2013; Heger and Jeschke 2014) is a new tool for research synthesis that can be used, along with systematic reviews and meta-analyses, for disentangling different key aspects of major hypotheses. The $\mathrm{HoH}$ approach can be seen as an extended systematic review where available empirical studies for a given major hypothesis are linked to hierarchically divided sub-hypotheses of the major hypothesis. An $\mathrm{HoH}$ is a special case of ontology. "Ontologies are formal models that define concepts and their relationships within a scientific domain" (p. 160 in Madin et al. 2008), and we agree with Madin et al. (2008) that their wider usage would advance ecological enquiry. Thus far, the $\mathrm{HoH}$ approach has been applied in detail to the enemy release hypothesis (Heger and Jeschke 2014); a first application has been presented in Jeschke et al. (2012), and for some critical comments on the approach see Farji-Brener and Amador-Vargas (2014).

In view of the contradictory results presented so far for IMH, our objectives are: (1) to apply the $\mathrm{HoH}$ approach in order to differentiate key aspects of IMH and represent these as sub-hypotheses of IMH, (2) to link empirical studies on IMH to these sub-hypotheses, (3) to evaluate the level of support for the different sub-hypotheses, and (4) to identify current gaps to guide future research.

\section{Methods}

To identify empirical studies on IMH, we searched the ISI Web of Science database for all publications citing Simberloff and Von Holle (1999) until 21 November
2014. Such a search is possible for IMH, as the publication by Simberloff and Von Holle (1999) is clearly recognized in the field as the first and single paper coining the term "invasional meltdown"; therefore, most studies testing IMH are likely referring to it. We did not consider books, which often do not report primary results, nor theoretical studies, because we restricted our analyses to empirical tests of IMH. We also excluded meta-analyses and reviews because these articles do not provide original results and including them would result in double-counting empirical findings.

We screened 637 papers citing Simberloff and Von Holle (1999). Of those, we identified 150 relevant empirical studies (i.e., studies reporting any interaction among at least two non-native species) that were included in the analysis. Following Heger and Jeschke (2014), we classified the evidence reported in each of the 150 studies as either supporting (i.e., positive effect among the studied non-native species), questioning (i.e., not supporting; negative effect among the studied non-native species), or being undecided (i.e., inconclusive evidence, e.g., a non-native species negatively affects growth but enhances survival of another non-native species). In other words, we scored each empirical test of IMH at one of these three levels. We did so by considering all provided evidence, particularly effect sizes reported in the studies. Our approach is distinct from vote counting where empirical tests are classified based only on the statistical significance they report (Borenstein et al. 2009; Koricheva et al. 2013). Vote counting has additional shortcomings and should be avoided (see Koricheva et al. 2013, p. 6 for more details). An alternative approach to the one applied here would be to use effect sizes directly, but it is unclear to which degree effect size values are comparable across sub-hypotheses, taxonomic groups, ecological levels and spatiotemporal scales. We thus decided to apply a three-level ordinal scoring approach.

We created the $\mathrm{HoH}$ by dividing IMH into subhypotheses using the following criteria:

1. Type of interaction, classified as either: (1.1) $\mathrm{A} \rightarrow \mathrm{B}$, where two non-native species interact and only one is affected, with no evidence of effect for the second (e.g., direct facilitation); (1.2) $\mathrm{A} \leftrightarrow \mathrm{B}$, where two non-native species interact and both species are affected (e.g., 
mutualism); or (1.3) multi-species interaction, that is an interaction network between three or more non-native species (e.g., one species affects the interaction between the second and third species).

2. Ecological level, classified as either: (2.1) individual, (2.2) population, (2.3) community, or (2.4) ecosystem level. This criterion relates to the measured parameter that was affected by the respective interaction (see 3 ).

3. For the individual, population and community levels, the diversity of available studies made it necessary to subdivide them further according to what was affected by the respective interaction:

Individual level: (2.1.1) resource (e.g., food source, feeding preference, predation, herbivory), (2.1.2) survival, growth or reproduction, (2.1.3) dispersal of individuals, (2.1.4) impact on individuals of native species.

Population level: (2.2.1) abundance, density or biomass, (2.2.2) population dispersal, (2.2.3) impact on native population.

Community level: (2.3.1) composition, (2.3.2) richness (2.3.3) diversity (2.3.4) impact on native community.

For six papers (see ESM Appendix 1), it was not possible to identify the variable used to quantify the effect of the interaction between the involved nonnative species; thus these studies were excluded from the analysis of "effect of interactions" sub-hypothesis (they were included for other analyses).

Regarding the non-native species involved, we additionally recorded whether they historically belong to the same native range (an indication of coevolution) (information classified according to the study); the immediacy of the interaction (that is, whether their interactions were direct or indirect, indirect interactions are the ones where species $\mathrm{A}$ alters the effect that species B has on species C); the habitat (terrestrial, freshwater, marine); taxonomic group (eubacteria/archaea/viruses, plants, algae, fungi; invertebrates subdivided into crustaceans, insects, mollusks, other invertebrates; vertebrates subdivided into fishes, amphibians, reptiles, birds and mammals); and the number of non-native species investigated. We divided the studies per group to check whether IMH support has been biased toward any ecosystem or some specific group of organism.
We also recorded which research method was applied (experiment or observation; conducted in the field, enclosure [including exclosure and common garden], or in the laboratory) and if the evidence provided was analyzed quantitatively with statistics, quantitatively without statistics (e.g., studies that only graphically plot data and/or include simple descriptive statistics such as averages), or only qualitatively (only nonnumerical information is presented). The above-mentioned analyses regarding methodological issues of the studies were conducted to verify the robustness of IMH tests. For example, controlled experiments employing quantitative (statistical) analyses may be considered more robust than purely observational studies based on descriptive analyses. And last, we recorded year of publication to identify possible changes in hypothesis relevance as evidence is gathered over the years. To do so, we additionally compared the number of studies found in our survey with the number of published papers on invasion biology indexed in the ISI Web of Science database. This additional search for general invasion biology studies was done using the key-words: species AND inva* OR introduced OR alien OR exotic OR nonnative OR non-indigenous.

The studies differ in several important aspects (research method, number of species investigated, type of interaction, ecological level), and these are of major importance when one evaluates IMH. We thus weighted studies according to these aspects, adapting the formula suggested by Heger and Jeschke (2014) for study weight $w$ :

$w=m \times \sqrt{n} \times i \times j$,

where, $m$ is a score for the research method ( 1 for observational enclosure studies, 2 for observational field studies or experimental laboratory studies, 4 for experimental enclosure studies and 8 for experimental field studies), $n$ is the number of focal non-native species (capped at a maximum value of 100), $i$ is a score for the type of interaction (1 for A $\rightarrow$ B studies, 3 for $\mathrm{A} \leftrightarrow \mathrm{B}$ studies, 8 for multi-species interactions) and $j$ is a score for the ecological level ( 1 for individual studies, 2 for population studies, 6 for community studies and 8 for ecosystem studies). Although the exact value of these weights is somewhat arbitrary, we consider it reasonable to assign weights based on the importance of multi-species versus two-species 
interactions and community- or ecosystem-studies versus studies at the level of individuals or populations that we outlined in the Introduction. For research method and ecological level, studies sometimes applied to more than one category, and the highest value was used for weight calculations in these cases. For example, one study might have conducted experiments both in the field and lab; for such cases scores were not added, but we used the score for the highest, in this case for experiments conducted in the field. These scores for calculating $w$ were chosen based on our interpretation of importance to IMH. In our case, the weights varied from 3 to 1024 (Appendix Fig. 3).

To avoid inflation of the sample size due to weight calculations, proportional weights were used by dividing the separate sum of weights supporting, questioning or being undecided for a given subhypothesis by the total sum of weights of that subhypothesis. This result was multiplied by the sample size number of the sub-hypothesis and rounded to whole numbers (following Maletta 2007; Heger and Jeschke 2014).

To test whether empirical support differs between sub-hypotheses, we performed Mann-Whitney U-tests. Chi square tests were performed to assess whether results supporting, questioning, or being undecided deviate from an equal distribution within each sub-hypothesis. If statistically significant, posthoc comparisons between supporting and questioning studies were carried out.

\section{Results}

Of the 150 relevant empirical studies on IMH that we identified, $63.3 \%(\mathrm{n}=95)$ supported the hypothesis, $23.3 \%(\mathrm{n}=35)$ questioned it, and $13.3 \%(\mathrm{n}=20)$ were considered undecided, as they showed both evidence for and against IMH (Appendix Table 3). When the weights given for the studies were considered, a similar pattern was found with $63.5 \%$ supporting, $21.0 \%$ questioning, and $15.5 \%$ being undecided (Table 1). The majority of studies were observational field studies $(38.6 \%, \mathrm{n}=85)$, followed by experimental field studies $(31.8 \%, \mathrm{n}=70)$ (Appendix Fig. 4), and most studies provided quantitative data together with statistical analyses $(90.7 \%, \mathrm{n}=136)$.

Analyzing weighted and unweighted data for each type of interaction separately, A $\rightarrow$ B interactions $(\mathrm{n}=58)$ and multi-species interactions $(\mathrm{n}=58)$ present the majority of studies supporting IMH, and for both categories the majority of studies were supportive. For $\mathrm{A} \leftrightarrow \mathrm{B}(\mathrm{n}=34)$ there was no statistical difference in the number of studies supporting and questioning IMH (Fig. 1a, Appendix Table 3 and Table 1). When sub-hypotheses were divided by ecological level, most studies still support IMH within each hierarchical level (Fig. 1b, Appendix Table 3 and Table 1). The majority of studies found were on individual $(44.5 \%, \mathrm{n}=89)$ and population levels (43.5\%, $\mathrm{n}=87$ ), followed by community level $(10.5 \%, \mathrm{n}=21)$; only three studies were done at the ecosystem level (1.5\%). Finally, the support for IMH considering the effects of the interactions was also significant for all comparisons, i.e., where more than five studies were found (Appendix Table 3 and Table 1).

The HoH illustrates the number of studies and level of support for different sub-hypotheses (Fig. 2). Although most sub-hypotheses of IMH are empirically supported, the $\mathrm{A} \leftrightarrow \mathrm{B}$ type of interaction at the population level is not supported for three subhypotheses. At the individual level, studies showing two species negatively affecting each other's survival, growth and/or reproduction constitute the majority in their category, thus also questioning IMH.

A significantly lower level of support was found for interacting non-native species that originated from the same native range as compared to species with no range overlap and thus no indication for coevolution ( $n=43$ ) (Fig. 1c). However, in nearly half of the studies $(49.7 \%, \mathrm{n}=75)$, this information was not available. When we compared evidence from direct $(52.4 \%, \mathrm{n}=87)$ or indirect $(33.7 \%, \mathrm{n}=56)$ interactions between non-native species, we found no significant difference (Fig. 1d). In both cases, there was significantly more weighted evidence supporting than questioning the hypothesis (Table 2 and Appendix Table 4).

When we take into account particular habitats, we find that most empirical tests of IMH were carried out in terrestrial ecosystems $(63.1 \%, \mathrm{n}=94)$. Freshwater and marine habitats were studied in only $32(21.5 \%)$ and $23(15.4 \%)$ tests, respectively. No significant differences in the level of support were found among habitats (Fig. 1e, Table 2 and Appendix Table 4). As for taxonomic groups, plants and algae (39.9\%, $\mathrm{n}=89)$ and invertebrates $(37.2 \%, \mathrm{n}=83)$ had more 
Table 1 Weighted evidence from empirical tests supporting, questioning or being undecided about IMH for each interaction type, ecological level and effect of interaction with $\chi^{2}$ values for comparison of the distribution of the three categories to an equal distribution. $\chi^{2}$ tests were only conducted for comparisons with more than five studies. Binomial tests comparing the proportion of supporting versus questioning studies were conducted when $\chi^{2}$ tests were significant $(p<$ 0.05). Significant values are highlighted in bold

\begin{tabular}{|c|c|c|c|c|c|c|}
\hline & $\mathrm{n}$ & Supporting (\%) & Undecided (\%) & Questioning (\%) & $\chi^{2}$ & Binomial test \\
\hline Total & 150 & 63.5 & 15.5 & 21.0 & $<0.001$ & $<0.001$ \\
\hline $\mathrm{A} \rightarrow \mathrm{B}$ & 58 & 77.1 & 9.8 & 13.1 & $<0.001$ & $<0.001$ \\
\hline $\mathrm{A} \leftrightarrow \mathrm{B}$ & 34 & 51.4 & 5.7 & 43.0 & 0.002 & 0.723 \\
\hline Multi Spp. & 58 & 64.0 & 17.6 & 18.4 & $<0.001$ & $<0.001$ \\
\hline Individual & 89 & 58.7 & 20.6 & 20.7 & $<0.001$ & $<0.001$ \\
\hline Resource & 26 & 72.3 & 27.7 & 0.0 & $<0.001$ & $<0.001$ \\
\hline Survival/Growth/Reproduction & 50 & 55.3 & 19.8 & 24.9 & 0.002 & 0.011 \\
\hline Dispersal & 12 & 88.9 & 8.9 & 2.2 & $<0.001$ & $<0.001$ \\
\hline Impact & 6 & 41.1 & 0.0 & 58.9 & - & - \\
\hline Population & 87 & 70.9 & 16.1 & 13.0 & $<0.001$ & $<0.001$ \\
\hline Abundance/Density/Biomass & 75 & 65.5 & 19.7 & 14.7 & $<0.001$ & $<0.001$ \\
\hline Dispersal & 3 & 92.5 & 7.5 & 0.0 & - & - \\
\hline Impact & 12 & 97.6 & 0.0 & 2.4 & $<0.001$ & $<0.001$ \\
\hline Community & 21 & 71.3 & 8.9 & 19.8 & $<0.001$ & 0.001 \\
\hline Composition & 4 & 58.8 & 41.2 & 0.0 & - & - \\
\hline Richness & 10 & 87.3 & 6.9 & 5.9 & 0.002 & 0.011 \\
\hline Diversity & 1 & 100 & 0.0 & 0.0 & - & - \\
\hline Impact & 7 & 98.3 & 0.0 & 1.7 & - & - \\
\hline Ecosystem & 3 & 100.0 & 0.0 & 0.0 & - & - \\
\hline
\end{tabular}

studies supporting than questioning, whereas for vertebrates $(22.9 \%, \mathrm{n}=51)$ there was no significant difference (Table 2 and Appendix Table 4). Overall, studies focusing on invertebrates showed a significantly higher level of support than those focusing on vertebrates (Fig. 1f).

Analyzing the temporal pattern of publications on IMH, we found no clear trend in level of support over time (Appendix Fig. 5). The increase in number of publications on IMH seems to follow the general trend for the discipline of invasion biology (Appendix Fig. 6).

\section{Discussion}

There is high overall support for IMH

The HoH approach allowed us to identify differences in the number of studies investigating different subhypotheses of IMH as well as differences in the levels of empirical support. The general results and majority of sub-hypotheses tested showed an evident dominance of studies supporting IMH. This result was independent of whether unweighted or weighted data were used.

We did not observe a "decline effect" where empirical support declines over time (cf. Jeschke et al. 2012). Such an effect can be caused by publication bias; for example, supporting evidence is more interesting and easier to publish at first, but once a hypothesis has become established and widely used, questioning evidence becomes more interesting and easier to publish. It can also be caused by differences in support for different taxa; for instance, a hypothesis is first tested for plants where it is generally supported after which it is tested for other taxonomic groups with lower support. We have not found such an effect for IMH. Also, there has been an overall increase in the number of studies on IMH through time.

Our results contrast with those of Jackson (2015). However, the two studies are not directly comparable. Jackson's meta-analysis was more specific, not covering all aspects of IMH and thus based on a smaller 


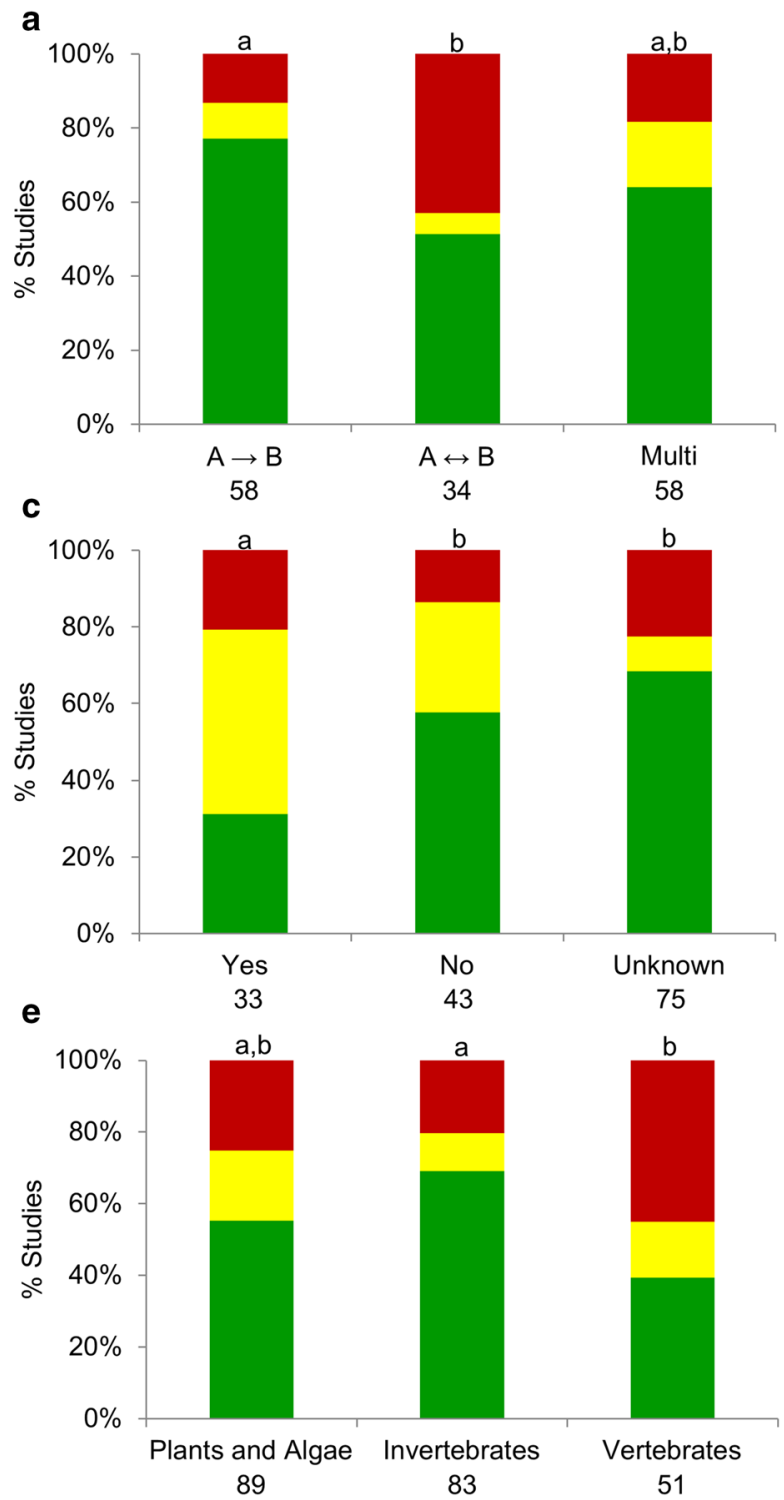

Fig. 1 Weighted data on level of empirical support for $\mathbf{a}$ different types of interactions, $\mathbf{b}$ ecological level, $\mathbf{c}$ non-native species coevolution, $\mathbf{d}$ immediacy of interaction, $\mathbf{e}$ habitats, and

dataset ( $\mathrm{n}=57$ vs. 150 here). She assessed (1) how non-natives influence one another, based on data on non-natives' performances when living together and separately from each other, and (2) how non-natives' interactions affect one another's ecological impact on ecosystems. In addition, different criteria to search papers were used, only interactions of animals were assessed, and the analyses were done differently (meta-analysis vs. our approach based on the hierarchy of hypotheses).
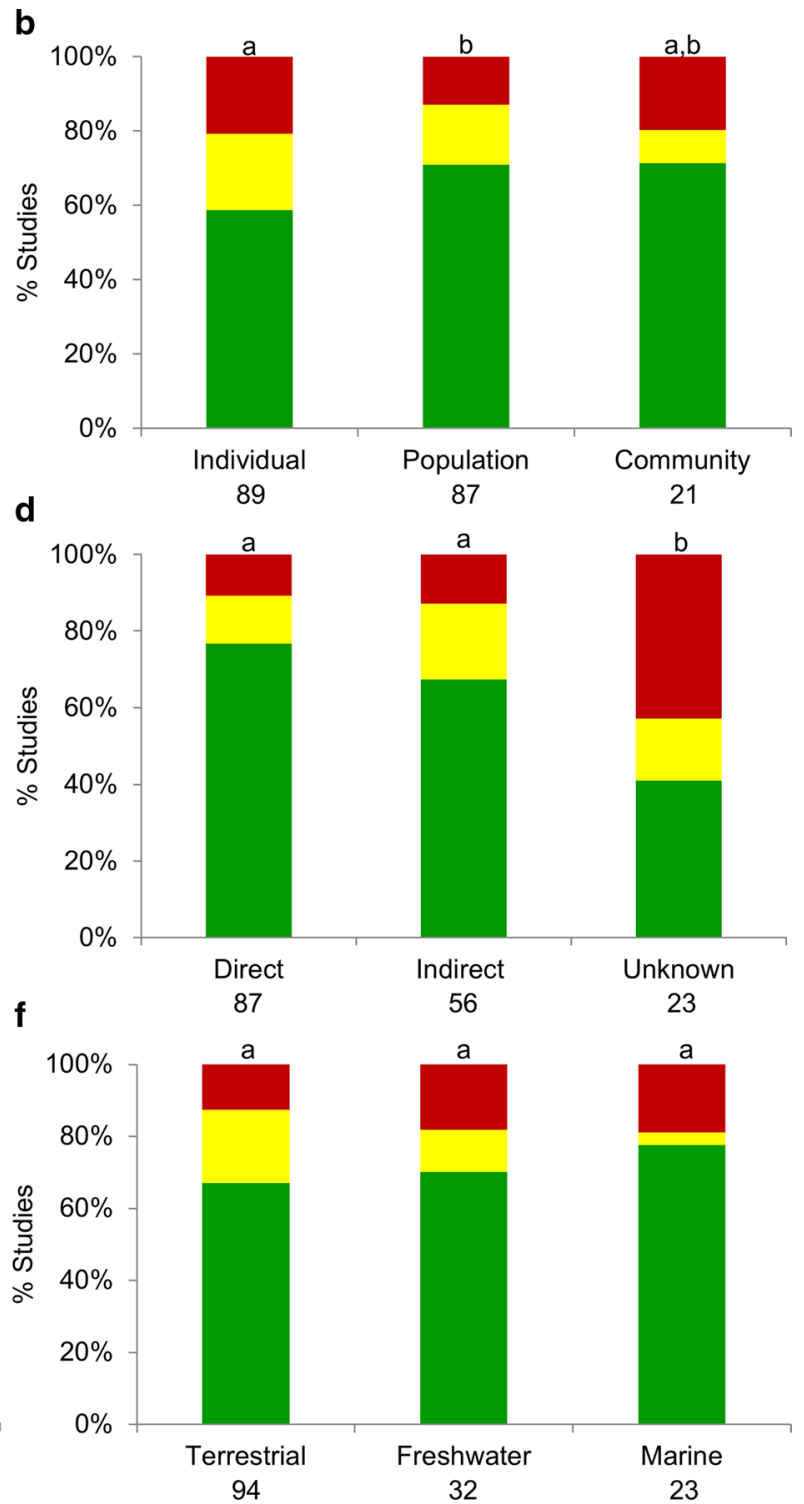

f taxonomic focus. Letters above bars indicate significant differences (U-tests, $p<0.05$ ). Numbers below bars indicate sample size

We highlight four studies with high weights in our analysis supporting IMH (ESM Excel file). Their high score is attributed to documentation of multiple species interactions, community- or ecosystem-level evidence, and for conducting field experiments with evidence analyzed quantitatively with statistics. First, Jackson et al. (2014) identified both additive and synergistic ecosystem effects of non-native crayfishes. Second, Stanley et al. (2013) studied a network of beneficial direct and indirect interactions between 


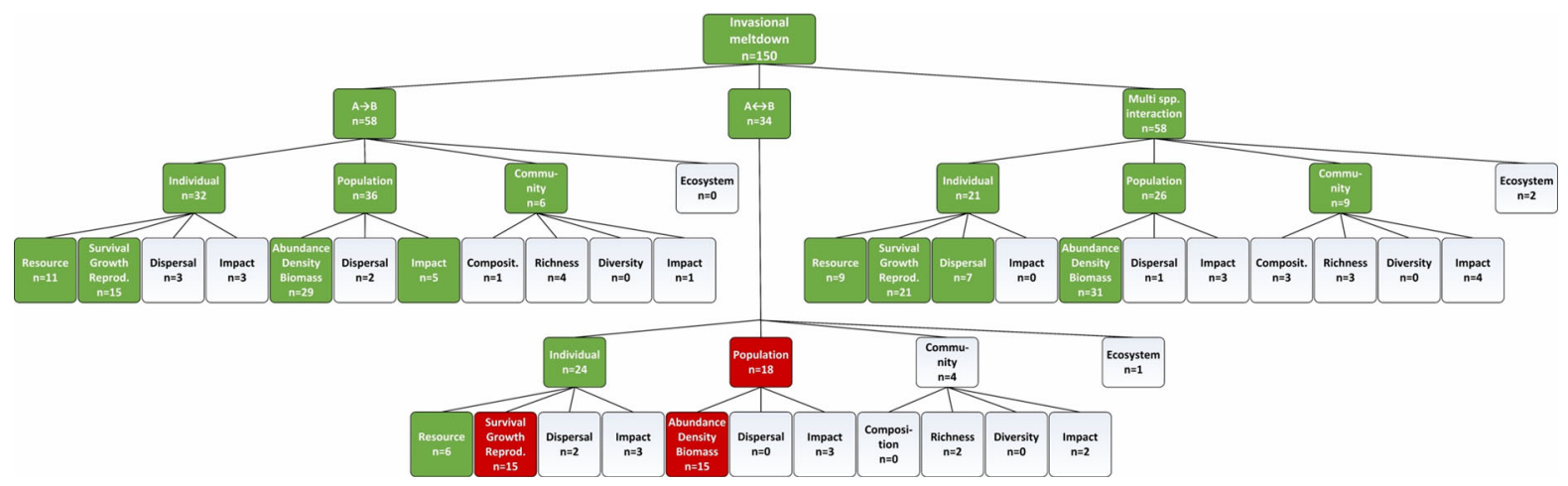

Fig. 2 Schematic illustration of the hierarchy of hypotheses $(\mathrm{HoH})$ for IMH. The $\mathrm{HoH}$ is structured according to three criteria: (1) type of interaction $(\mathrm{A} \rightarrow \mathrm{B}, \mathrm{A} \leftrightarrow \mathrm{B}$ and multi species interaction); (2) ecological level of evidence (individual, population, community and ecosystem); and (3) effect of interaction (resource, survival, growth, reproduction, dispersal, impact, abundance, density, biomass, composition, richness and diversity). Color codes indicate levels of empirical support, as follows: green boxes, $\mathrm{n} \geq 5$ and $>50 \%$ of weighted evidence supporting the sub-hypothesis; red boxes, $\mathrm{n} \geq 5$ and $>50 \%$ of weighted evidence questioning the subhypothesis; white boxes, all other cases (all $\mathrm{n}<5$, so no comparisons were made here)
Table 2 Weighted evidence from empirical tests supporting, questioning or being undecided about IMH for non-native species coevolution, direct and indirect effects, habitats and taxonomic groups with $\chi^{2}$ values for comparison of the distribution of the three categories to an equal distribution.
Binomial tests comparing the proportion of supporting versus questioning studies were conducted when $\chi^{2}$ tests were significant $(p<0.05)$. Significant values are highlighted in bold

\begin{tabular}{|c|c|c|c|c|c|c|}
\hline & $\mathrm{n}$ & Supporting (\%) & Undecided (\%) & Questioning (\%) & $\chi^{2}$ & Binomial test \\
\hline With coevolution & 33 & 31.1 & 48.2 & 20.7 & 0.148 & - \\
\hline Without coevolution & 43 & 57.7 & 28.8 & 13.5 & 0.001 & $<0.001$ \\
\hline Unknown & 75 & 68.3 & 9.1 & 22.6 & $<0.001$ & $<0.001$ \\
\hline Direct effect & 87 & 76.7 & 12.6 & 10.8 & $<0.001$ & $<0.001$ \\
\hline Indirect effect & 56 & 67.3 & 19.8 & 12.8 & $<0.001$ & $<0.001$ \\
\hline Unknown & 23 & 41.0 & 16.1 & 42.9 & 0.269 & - \\
\hline Terrestrial & 94 & 67.1 & 20.3 & 12.6 & $<0.001$ & $<0.001$ \\
\hline Freshwater & 32 & 70.1 & 11.8 & 18.1 & $<0.001$ & 0.002 \\
\hline Marine & 24 & 77.6 & 3.4 & 18.9 & $<0.001$ & 0.002 \\
\hline Plants and algae & 89 & 55.1 & 20.2 & 24.78 & $<0.001$ & $<0.001$ \\
\hline Invertebrates & 83 & 69.1 & 10.5 & 20.4 & $<0.001$ & $<0.001$ \\
\hline Vertebrates & 51 & 39.4 & 15.6 & 45.0 & 0.024 & 0.647 \\
\hline
\end{tabular}

Argentine ants (Linepithema humile), scale insects (Saissetia oleae and Parasaissetia nigra) and boneseed (Chrysanthemoides monilifera monilifera) that are invasive in New Zealand, and their negative effects on the native invertebrate community. Finally, the combined findings of O'Dowd et al. (2003) and Green et al. (2011) showed that the mutualism between the introduced yellow crazy ant (Anoplolepis gracilipes) and introduced honeydew-secreting scale insects
(Tachardina aurantiaca and Coccus spp.) leads to a population burst of both species. In addition, the high abundance of the yellow crazy ant reduces local populations of the native red land crab, as the invasive ant kills the native crabs by spraying formic acid over their eyes and mouthparts. By extirpating the native crab population, the invasive ant creates an enemyfree space for the invasive giant African snail. The native crab is furthermore responsible for regulating 
seedling abundance and litter breakdown, hence the invasive snail also benefits from increased resources.

Some IMH sub-hypotheses are not empirically supported

Nonetheless, not all IMH sub-hypotheses are well supported by currently available evidence, e.g., studies looking at $\mathrm{A} \leftrightarrow \mathrm{B}$ interactions (see Fig. 4). There is much evidence for competition between species, possibly because for many decades competition was considered the main force structuring communities (Elton 1946; Diamond 1975; Ricklefs 1987; Gotelli and McCabe 2002; Richardson et al. 2000). On the other hand, there is substantial evidence suggesting that mutualistic interactions occur frequently among non-natives (reviewed by Richardson et al. 2000). It is possible that in the present global change scenario, positive interactions will increase in importance as posited by the stress-gradient hypothesis (Bertness and Callaway 1994; Kawai and Tokeshi 2007; He et al. 2013). The variety of positive $\mathrm{A} \leftrightarrow \mathrm{B}$ interactions found in our study (e.g., mycorrhizal associations, plant-pollinator interactions, ant-scale insects, seed dispersal) suggests that mutualisms are important in several invasion scenarios. However, the amount of evidence gathered so far on mutualism does not surpass evidence on competition.

Which aspects of IMH are currently not well addressed?

\section{Ecological level}

Although it was highlighted by Simberloff and Von Holle (1999) and later by Simberloff (2006) that invasional meltdown is a community-level phenomenon, there is currently scarce available evidence at this level. Indeed, out of 150 investigations, we found only 21 studies carried out at the community level. Still, the IM phenomenon is complex and information on other levels is of great importance to its understanding.

In addition to IM, there are many other important aspects of invasion biology at the community level (Shea and Chesson 2002; Simberloff 2004). For example, establishment and population increase of the non-native species are critical stages of the invasion process and directly depend on whether the recipient community provides niche opportunities (Shea and Chesson 2002). However, community-level phenomena are, in Lawton's (1999) words, "orders of magnitude more complicated" than population dynamics. Thus, data at individual and population levels can be more easily collected (together representing $88 \%$ of the IMH studies analyzed here). Our results show that individual-level evidence is not always in accordance with population-level evidence for IMH (see $\mathrm{A} \leftrightarrow \mathrm{B}$ interaction of Fig. 3a), therefore generalizations across ecological levels should be done carefully, and future research should focus on collecting community-level evidence (Simberloff 2004).

\section{Indirect effects}

Positive indirect effects were also poorly represented in our dataset. A challenge when one investigates species interactions is that the effect of interactions might vary along the network of interactions and across ecological levels. For example, consider an indirect interaction where one non-native species A reduces the population of an enemy $\mathrm{B}$ of another nonnative species C (Ricciardi 2001; Nuñez et al. 2008). If enemy $\mathrm{B}$ was also non-native and the study would look only at the direct interaction between A and B, IMH would be questioned. However, IMH would be supported when the study includes species $\mathrm{C}$, which would become indirectly facilitated by species $\mathrm{A}$ thanks to the suppression of its enemy B.

Indirect effects are often difficult to detect and measure because doing so requires a more complete look at the multitude of interactions one species might have within a community; therefore, they are often neglected (White et al. 2006). Indirect effects might also yield different interpretations at different ecological levels (e.g., Vitule et al. 2012 and references therein). Diet analysis and an enclosure experiment showed that a crayfish invasive to Europe consumed a non-native macrophyte, but on the other hand the macrophyte increased in biomass when the crayfish was present because the crayfish excluded macrophyte competitors (Chucholl 2013). In this case, a negative interaction was present at the individual level (measured as the presence of the non-native macrophyte in stomach contents), but a stronger positive outcome was observed at the population level (measured as the increase in biomass of the same non-native macrophyte). 


\section{Habitats and taxonomy}

Our results on habitats showed a predominance of studies in terrestrial systems. This bias is not restricted to IMH, as it follows the general pattern in invasion biology (Jeschke et al. 2012; Lowry et al. 2013). A better representation of aquatic habitats is important because they are known to host a large number of nonnative species and are under severe threat from invasion, particularly freshwater systems (Dudgeon et al. 2006; Havel et al. 2015; Gallardo et al. 2016). The high level of support for all habitats but the small number of studies in marine environments strengthens the need for underrepresented marine habitats to be studied.

We also found a taxonomic bias in the studies, as the majority focused on plants and terrestrial insects (see Pyšek et al. 2008; Jeschke et al. 2012 for similar results). Probably this bias is related to the ease of data collection for insect-plant interactions and the wide variety of positive interactions between them naturally (e.g., pollination). Studies on vertebrates showed lower support for IMH. We suspect this is due to the high number of consumptive and competitive interactions detected and to the fact that these interactions are more conspicuous than facilitative ones (Bertness and Callaway 1994), which is particularly important when one is studying large mobile organisms such as vertebrates.

Why do not more studies produce 'strong evidence' for IMH?

Despite the high level of support that we found for IMH overall, the majority of studies were not designed to test the hypothesis. Supporting information comes mainly from secondary results. For example, analyzing which species of bird dispersed seeds of an invasive shrub and if the seeds were viable after gut passage, Bartuszevige and Gorchov (2006) identified a non-native species as an important viable seed disperser. Their aim was not to evaluate IMH, but they found an important positive interaction between two non-native species, therefore supporting IMH. A shift towards replicated experimental designs is paramount to infer causal relationships between species interactions and the increasing rate of invasions and/or the synergistic impact upon the native community (Oksanen 2001).
A lack of studies on invasion rates

According to the original IMH, the ultimate community effect would be the accelerating rate of invasion resulting from species introductions and facilitations (Simberloff 2006; Von Holle 2011). Despite its importance for IMH, there are almost no studies with information on invasion rates (an exception is Wonham and Pachepsky 2006). This gap can be filled with long-term monitoring of species invasions. For example, Tecco et al. (2006) found higher non-native species richness under the canopy of a non-native shrub than under natives. If this is an ongoing process, long-term monitoring might reveal an increasing rate of invasions (see also Seebens et al. 2017).

Is co-evolution necessary for IM?

It has been hypothesized that coevolution might be important for IM, where non-native species should be more likely to facilitate coevolved species compared to native species (DeVanna et al. 2011), although this idea was not present in the original formulation by Simberloff and Von Holle (1999) (see also Simberloff 2006; Von Holle 2011). In these cases, coevolved species would more likely be involved in mutualistic interactions with species that they already interacted with in their native range. The importance of coevolution for IM remains a current question (Jackson 2015). In our analysis, studies on coevolved nonnative species showed lower support for IMH than studies on non-native species that did not coevolve (Fig. 1c). This agrees with Verdú et al. (2012) and Valiente-Banuet and Verdú (2013) who showed that facilitation is more common among distantly related species (i.e., species that have evolved separately). Hence, increasing phylogenetic distance among two species would result in larger facilitation, hence coevolution does not automatically favor an IM scenario. The level of eco-evolutionary experience (sensu Saul et al. 2013; Saul and Jeschke 2015) (i.e., adaptations accumulated during evolution to biotic interactions in a species' native range) that the nonnative species has is likely more important to the outcome of the new interaction. A high level of ecoevolutionary experience will favor IM only if previous interactions with archetypes of interaction partners were positive (Saul et al. 2013). 
Recommendations for future research

The fact that certain interacting species cause an invasional meltdown leading to wide community effects makes IMH an important research topic. However, we need to better understand how general and widespread IM is among taxa and environments, and which aspects of IMH are particularly common. A deeper knowledge of IM is crucial to further develop the hypothesis and direct future studies. We suggest that future studies focus on multi-species interactions at the community or ecosystem level, ultimately linking interactions to the increasing number of non-native species.

A next step would also be to link the $\mathrm{HoH}$ approach with formal meta-analytical tools. A challenge here is that it is not clear to what degree effect sizes are comparable across sub-hypotheses, taxonomic groups, ecological levels and spatiotemporal scales. This general question needs to be tackled. At least for given sub-hypotheses and given scales, combining the $\mathrm{HoH}$ approach with formal meta-analytical tools will be useful and should be explored in the future.

In conclusion, IMH appears to be widely supported along a wide array of habitats and organisms, but cases where a link between positive interactions and synergistic negative impacts, or increasing rates of invasion have been found are still rare. The $\mathrm{HoH}$ presented here can be continually updated, and thus progress in research on IMH can be monitored. An extended $\mathrm{HoH}$ for IMH is planned to be included in an online portal jointly with HoHs for other hypotheses. In this way, all researchers, managers and other interested people can access continually updated information about major hypotheses in invasion biology and other disciplines.
Acknowledgements This research was supported by R.R. Braga's CAPES (Cordenação de Aperfeiçoamento de Pessoal de Nível Superior) scholarship, a CNPq (Conselho Nacional de Desenvolvimento Científico e Tecnológico) grant to J.R.S. Vitule (JRSV: 310850/2012-6, 303776/2015-3; CNPq) and a DFG (Deutsche Forschungsgemeinschaft) grant to J.M. Jeschke (JE 288/9-1). L. Gómez-Aparicio was supported by the MICINN project INTERCAPA (CGL2014-56739-R). We would also like to thank S.M. Thomaz, R.D. Zenni, M.S. Dechoum, K.M. Campião, L.C. Gomes and V. Abilhoa and all members of LECUFPR for helpful suggestions on the manuscript.

Open Access This article is distributed under the terms of the Creative Commons Attribution 4.0 International License (http:// creativecommons.org/licenses/by/4.0/), which permits unrestricted use, distribution, and reproduction in any medium, provided you give appropriate credit to the original author(s) and the source, provide a link to the Creative Commons license, and indicate if changes were made.

\section{Appendix}

See Figs. 3, 4, 5, 6 and Tables 3 and 4.

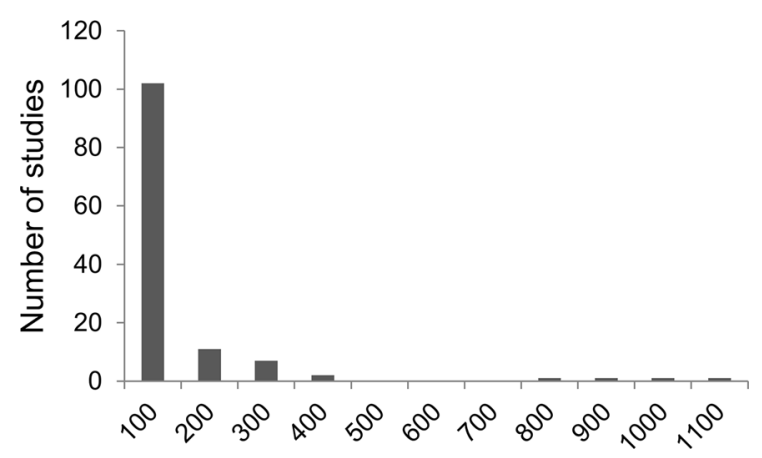

Fig. 3 Number of studies in different weight categories
Fig. 4 Percentage of studies using different research methods. Numbers above bars indicate sample sizes

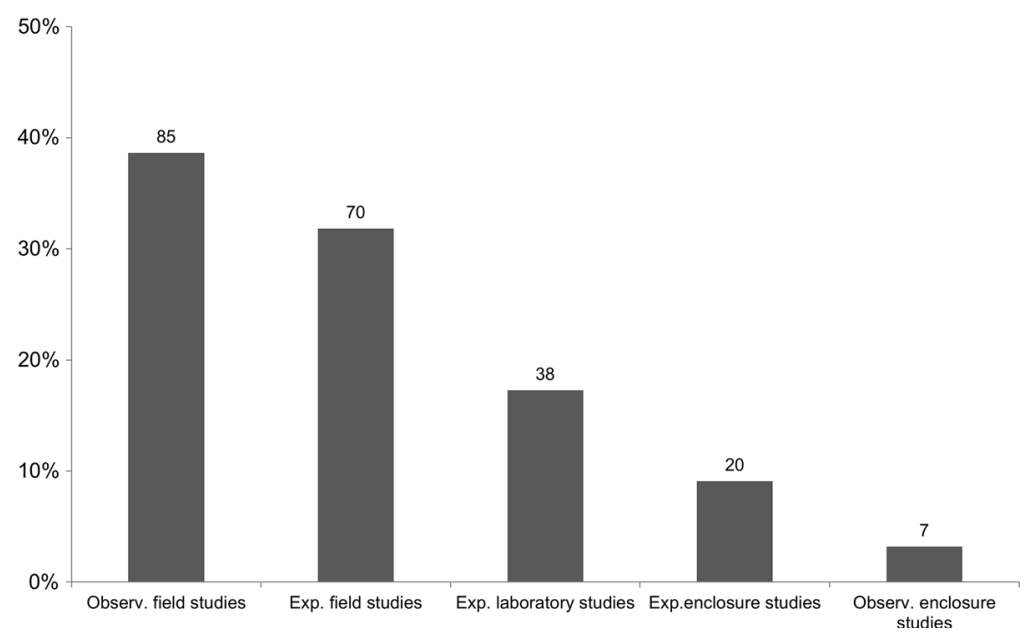




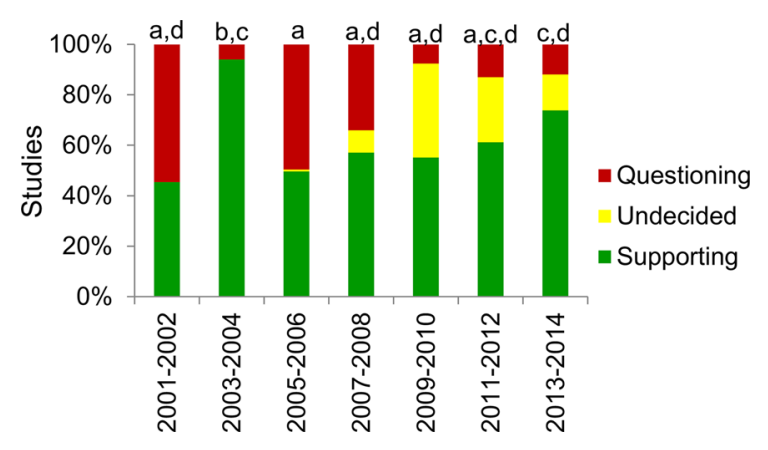

Fig. 5 Weighted data on level of empirical support over time. Letters above bars indicate significant differences (U-tests, $p<0.05)$

Fig. 6 Number of studies on IMH (red line) compared to number of studies on invasion biology (blue line) indexed on the ISI Web of Science database

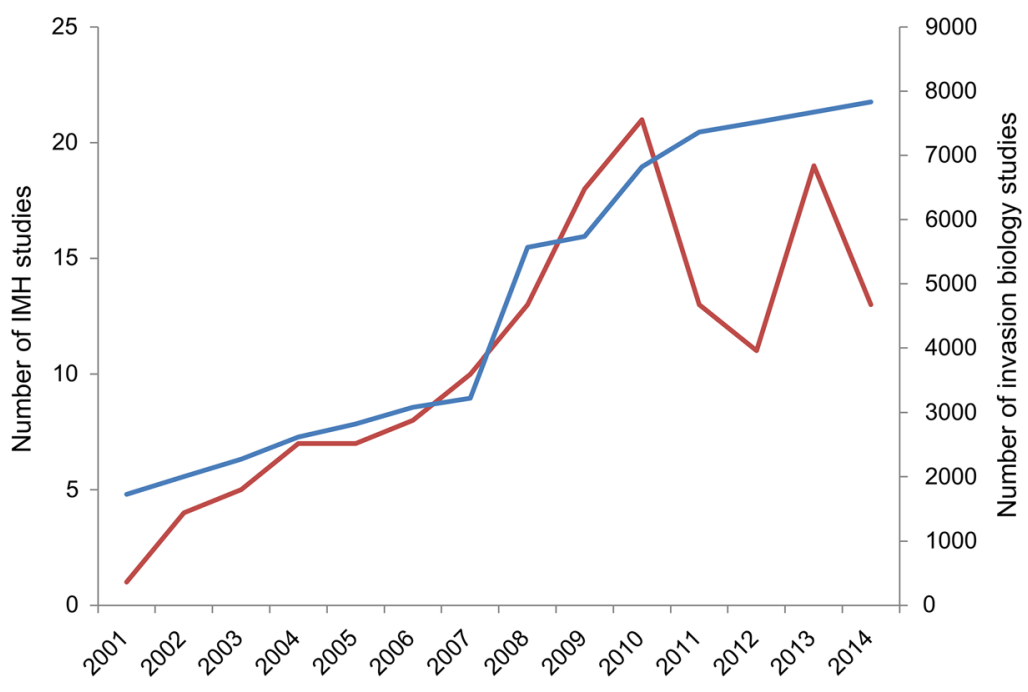

Table 3 Unweighted evidence from empirical tests supporting, questioning or being undecided about IMH for each interaction type, ecological level and effect of interaction with $\chi^{2}$ values for comparison of the distribution of the three categories to an equal distribution. $\chi^{2}$ tests were only

\begin{tabular}{|c|c|c|c|c|c|c|}
\hline & $\mathrm{N}$ & Supporting (\%) & Undecided (\%) & Questioning (\%) & $\chi^{2}$ & Binomial test \\
\hline Total & 150 & 63.3 & 13.3 & 23.3 & $<0.001$ & $<0.001$ \\
\hline $\mathrm{A} \rightarrow \mathrm{B}$ & 58 & 74.1 & 10.3 & 15.5 & $<0.001$ & $<0.001$ \\
\hline $\mathrm{A} \leftrightarrow \mathrm{B}$ & 34 & 52.9 & 5.9 & 41.2 & 0.002 & 0.479 \\
\hline Multi Spp. & 58 & 58.6 & 20.7 & 20.7 & $<0.001$ & 0.001 \\
\hline Individual & 89 & 60.7 & 13.5 & 25.8 & $<0.001$ & $<0.001$ \\
\hline Resource & 26 & 84.6 & 15.4 & 0.0 & $<0.001$ & $<0.001$ \\
\hline
\end{tabular}

conducted for comparisons with more than five studies. Binomial tests comparing the proportion of supporting versus questioning studies were conducted when $\chi^{2}$ tests were significant $(p<0.05)$. Significant values are highlighted in bold 
Table 3 continued

\begin{tabular}{|c|c|c|c|c|c|c|}
\hline & $\mathrm{N}$ & Supporting (\%) & Undecided (\%) & Questioning (\%) & $\chi^{2}$ & Binomial test \\
\hline Survival/Growth/Reproduction & 50 & 48.0 & 16.0 & 36.0 & 0.019 & 0.354 \\
\hline Dispersal & 12 & 83.3 & 8.3 & 8.3 & 0.001 & 0.006 \\
\hline Impact & 6 & 33.3 & 0.0 & 66.7 & 0.135 & - \\
\hline Population & 87 & 60.9 & 14.9 & 24.1 & $<0.001$ & $<0.001$ \\
\hline Abundance/Density/Biomass & 75 & 58.7 & 17.3 & 24.0 & $<0.001$ & $<0.001$ \\
\hline Dispersal & 3 & 66.7 & 33.3 & 0.0 & 0.367 & - \\
\hline Impact & 12 & 83.3 & 0.0 & 16.7 & $<0.001$ & 0.020 \\
\hline Community & 21 & 71.4 & 14.3 & 14.3 & 0.001 & 0.004 \\
\hline Composition & 4 & 75.0 & 25.0 & 0.0 & 0.173 & - \\
\hline Richness & 10 & 70.0 & 20.0 & 10.0 & 0.044 & 0.033 \\
\hline Diversity & 1 & 100 & 0.0 & 0.0 & 0.364 & - \\
\hline Impact & 7 & 85.7 & 0.0 & 14.3 & 0.011 & 0.058 \\
\hline Ecosystem & 3 & 100.0 & 0.0 & 0.0 & 0.049 & 0.083 \\
\hline
\end{tabular}

Table 4 Unweighted evidence from empirical tests supporting, questioning or being undecided about the invasional meltdown hypothesis for non-native species coevolution, direct and indirect effects, habitats and taxonomic groups with $\chi^{2}$ values for comparison of the distribution of the three categories to an equal distribution. $\chi^{2}$ tests were only conducted for comparisons with more than five studies. Binomial tests comparing the proportion of supporting versus questioning studies were conducted when $\chi^{2}$ tests were significant $(p<$ 0.05). Significant values are highlighted in bold

\begin{tabular}{|c|c|c|c|c|c|c|}
\hline & $\mathrm{n}$ & Supporting & Undecided & Questioning & $\chi^{2}$ & Binomial test \\
\hline With coevolution & 33 & 57.6 & 15.2 & 27.3 & $<0.001$ & 0.058 \\
\hline Without coevolution & 43 & 60.5 & 16.3 & 23.3 & $<0.001$ & 0.007 \\
\hline Unknown & 75 & 66.7 & 12.0 & 21.3 & $<0.001$ & $<0.001$ \\
\hline Direct effect & 87 & 72.4 & 12.6 & 14.9 & $<0.001$ & $<0.001$ \\
\hline Indirect effect & 56 & 55.4 & 12.5 & 32.1 & $<0.001$ & 0.063 \\
\hline Unknown & 23 & 47.8 & 32.1 & 26.1 & 0.336 & - \\
\hline Terrestrial & 94 & 70.2 & 14.9 & 14.9 & $<0.001$ & $<0.001$ \\
\hline Freshwater & 32 & 46.9 & 12.5 & 40.6 & 0.039 & - \\
\hline Marine & 24 & 60.9 & 8.7 & 30.4 & $<0.001$ & 0.126 \\
\hline Plants and algae & 89 & 64.0 & 21.3 & 14.6 & $<0.001$ & $<0.001$ \\
\hline Invertebrates & 83 & 67.5 & 10.8 & 21.7 & $<0.001$ & $<0.001$ \\
\hline Vertebrates & 51 & 62.7 & 7.8 & 29.4 & $<0.001$ & 0.013 \\
\hline
\end{tabular}

\section{References}

Bartuszevige AM, Gorchov DL (2006) Avian seed dispersal of an invasive shrub. Biol Invasions 8:1013-1022

Bertness MD, Callaway R (1994) Positive interactions in communities. Trends Ecol Evol 9:191-193

Borenstein M et al (2009) Introduction to meta-analysis. Wiley, Chichester

Brooker RW et al (2008) Facilitation in plant communities: the past, the present, and the future. J Ecol 96:18-34

Bruno JF et al (2003) Inclusion of facilitation into ecological theory. Trends Ecol Evol 18:119-125
Chucholl C (2013) Feeding ecology and ecological impact of an alien 'warm water' omnivore in cold lakes. Limnologica 43:219-229

DeVanna KM et al (2011) An alternative hypothesis to the invasional meltdown in the Laurentian Great Lakes region: general facilitation by Dreissena. J Great Lakes Res 37:632-641

Diamond JM (1975) Assembly of species communities. In: Cody ML, Diamond JM (eds) Ecology and evolution of communities. Harvard University Press, Cambridge, pp 342-444 
Dudgeon D et al (2006) Freshwater biodiversity: importance, threats, status and conservation challenges. Biol Rev 81:163-182

Elton C (1946) Competition and the structure of ecological communities. J Anim Ecol 15:54-68

Farji-Brener AG, Amador-Vargas S (2014) Hierarchy of hypotheses or cascade of predictions? A comment on Heger et al. (2013). Ambio 43:1112-1114

Gallardo B et al (2016) Global ecological impacts on invasive species in aquatic ecosystems. Glob Change Biol 22:151-163

Gotelli NJ, McCabe DJ (2002) Species co-occurrence: a metaanalysis of Diamond's assembly rules model. Ecology 83:2091-2096

Green PT et al (2011) Invasional meltdown: invader-invader mutualism facilitates a secondary invasion. Ecology 92:1758-1768

Halpern BS et al (2007) Incorporating positive interactions in aquatic restoration and conservation. Front Ecol Environ $5: 153-160$

Havel JE et al (2015) Aquatic invasive species: challenges for the future. Hydrobiologia 750:147-170

He Q et al (2013) Global shifts towards positive species interactions with increasing environmental stress. Ecol Lett 16:695-706

Heger T, Jeschke JM (2014) The enemy release hypothesis as a hierarchy of hypotheses. Oikos 123:741-750

Heger $\mathrm{T}$ et al (2013) Conceptual frameworks and methods for advancing invasion ecology. Ambio 42:527-540

Jackson MC (2015) Interactions among multiple invasive animals. Ecology 96:2035-2041

Jackson MC et al (2014) Niche differentiation among invasive crayfish and their impacts on ecosystem structure and functioning. Freshw Biol 59:1123-1135

Jeschke JM et al (2012) Support for major hypotheses in invasion biology is uneven and declining. NeoBiota 14:1-20

Kawai T, Tokeshi M (2007) Testing the facilitation-competition paradigm under the stress-gradient hypothesis: decoupling multiple stress factors. Proc R Soc B Biol Sci 274:2503-2508

Koricheva J, Gurevitch J, Mengerson K (2013) Handbook of meta-analysis in ecology and evolution. Princeton University Press, Princeton

Lawton JH (1999) Are there general laws in ecology? Oikos 84:177-192

Lortie CJ, Callaway RM (2009) David and Goliath: comparative use of facilitation and competition studies in the plant ecology literature. Web Ecol 9:54-57

Lowry E et al (2013) Biological invasions: a field synopsis, systematic review, and database of the literature. Ecol Evol 3:182-196

Madin JS et al (2008) Advancing ecological research with ontologies. Trends Ecol Evol 23:159-168

Maletta H (2007) Weighting. www.spsstools.net/Tutorials/. Accessed 11 Sept 2013

Nuñez MA et al (2008) Enemy release or invasional meltdown? Deer preference for exotic and native trees on Isla Victoria, Argentina. Austral Ecol 33:317-323
O'Dowd DJ et al (2003) Invasional 'meltdown' on oceanic island. Ecol Lett 6:812-817

Oksanen L (2001) Logic of experiments in ecology: is pseudoreplication a pseudoissue? Oikos 94:27-38

Pyšek P et al (2008) Geographical and taxonomic biases in invasion ecology. Trends Ecol Evol 23:237-244

Ricciardi A (2001) Facilitative interactions among aquatic invaders: is an "invasional meltdown" occurring in the Great Lakes? Can J Fish Aquat Sci 58:2513-2525

Richardson DM et al (2000) Plant invasions-the role of mutualisms. Biol Rev 75:65-93

Ricklefs RE (1987) Community diversity: relative roles of local and regional processes. Science 235:167-171

Saul W-C, Jeschke JM (2015) Eco-evolutionay experience in novel species interactions. Ecol Lett 18:236-245

Saul W-C, Jeschke JM, Heger T (2013) The role of eco-evolutionary experience in invasion success. NeoBiota 17:57-74

Seebens $\mathrm{H}$ et al (2017) No saturation in the accumulation of alien species worldwide. Nat Commun 8:14435

Shea K, Chesson P (2002) Community ecology theory as a framework for biological invasions. Trends Ecol Evol 17:170-176

Simberloff D (2004) Community ecology: is it time to move on? Am Nat 163(6):787-799

Simberloff D (2006) Invasional meltdown 6 years later: important phenomenon, unfortunate metaphor, or both? Ecol Lett 9:912-919

Simberloff D, Von Holle B (1999) Positive interactions of nonindigenous species: invasional meltdown? Biol Invasions 1:21-32

Soliveres $\mathrm{S}$ et al (2015) Moving forward on facilitation research: response to changing environments and effects on the diversity, functioning and evolution of plant communities. Biol Rev 90:297-313

Stachowicz JJ (2001) Mutualism, facilitation, and the structure of ecological communities. Bioscience 51:235-246

Stanley MC et al (2013) Invasive interactions: can Argentine ants indirectly increase the reproductive output of a weed? Arthropod-Plant Interact 7:59-67

Tecco PA et al (2006) Positive interaction between invasive plants: the influence of Pyracantha angustifolia on the recruitment of native and exotic woody species. Austral Ecol 31:293-300

Valiente-Banuet A, Verdú M (2013) Plant facilitation and phylogenetics. Annu Rev Ecol Evol Syst 44:347-366

Verdú M et al (2012) Phylogenetic relatedness as a tool in restoration ecology: a meta-analysis. Proc R Soc B 279:1761-1767

Vitule JRS et al (2012) Revisiting the potential conservation value of non-native species. Conserv Biol 26:1153-1155

Von Holle B (2011) Invasional meltdown. In: Simberloff D, Rejmánek M (eds) Encyclopedia of biological invasion. University of California Press, Los Angeles, pp 360-364

White EM et al (2006) Biotic indirect effects: a neglected concept in invasion biology. Divers Distrib 12:443-455

Wonham MJ, Pachepsky E (2006) A null model of temporal trends in biological invasion records. Ecol Lett 9:663-672 